\title{
Regularity of rainfall timing across Ethiopia: implications for crop production
}

\section{Other Conference Item}

Author(s):

Wakjira, Mosisa; Molnar, Darcy; Peleg, Nadav; Six, Johan; Molnar, Peter (D)

Publication date:

2021

Permanent link:

https://doi.org/10.3929/ethz-b-000520699

Rights / license:

Creative Commons Attribution 4.0 International

Originally published in:

EGUsphere, https://doi.org/10.5194/egusphere-egu21-9279 
EGU21-9279, updated on 15 Dec 2021

https://doi.org/10.5194/egusphere-egu21-9279

EGU General Assembly 2021

(c) Author(s) 2021. This work is distributed under

the Creative Commons Attribution 4.0 License.

\title{
Regularity of rainfall timing across Ethiopia: implications for crop production
}

\author{
Mosisa Wakjira ${ }^{1,2}$, Darcy Molnar ${ }^{1}$, Nadav Peleg ${ }^{1}$, Johan Six ${ }^{2}$, and Peter Molnar ${ }^{1}$ \\ ${ }^{1}$ Institute of Environmental Engineering, Hydrology and Water Resources Management Group, ETH Zurich, Zurich, \\ Switzerland (wakjira@ifu.baug.ethz.ch) \\ ${ }^{2}$ Institute of Agricultural Sciences, Sustainable Agroecosystems Group, ETH Zurich, Zurich, Switzerland
}

Rainfall timing is a key parameter that farmers rely on to match the cropping season with the time window over which seasonal precipitation provides adequate soil moisture to meet plant growth demand. The unpredictability of rainfall timing affects the selection of an optimal growing season, and hence crop production in regions where rainfed agriculture (RFA) is practiced. In this study, we (a) map rainfall timing, and its interannual variability and changes over RFA areas across Ethiopia for the period 1981-2010, and (b) explore the impact of variability in rainfall timing on cereal crop production in the period 1995-2010.

For the mapping of rainfall timing, we used the quasi-global CHIRPS precipitation dataset over Ethiopia. We use information entropy on monthly rainfall to define the rainfall seasonality metrics, i.e. the relative entropy and dimensionless seasonality index, and map them in space. For rainfall timing attributes, we determine the onset, cessation, and length of the wet season from LOESSsmoothed cumulative pentad rainfall anomalies for each hydrological year. Changes in seasonality metrics and rainfall timing attributes are analyzed using non-parametric methods. We show that high seasonality (unimodal rainfall regime) is located in the northern part of the Ethiopian RFA area where high annual rainfall and high relative entropy are coincident, and where the onset of the rainfall season varies between mid-April to late-June and cessation occurs between midSeptember to late-October. Low seasonality in the southern part of the Ethiopian RFA area shows low relative entropy regardless of the annual rainfall total. We observed a considerable interannual variability both in seasonality and rainfall timing over the study period, especially in the onset and length of the wet season. The length of the wet season and magnitude of seasonal rainfall are predominantly controlled by the timing of rainfall onset.

For the impacts of rainfall timing on crop production, we used cereal crop production data from the Central Statistical Agency of Ethiopia for the period 1995-2010 in 45 administrative zones. We carried out a parametric correlation analysis between rainfall timing and rescaled and de-trended crop production anomalies. We observe that anomalies in seasonal cereal crop production in RFA areas are significantly correlated with anomalies in rainfall onset (negatively) and the length of the wet season (positively), with a regional average production loss of 3\% per pentad of late rainfall onset, and $2.7 \%$ per pentad of shorter length of the wet season. Seasonal rainfall is less strongly 
correlated with cereal crop production anomalies compared to the rainfall onset. These results show that the interannual variability in rainfall timing (start of the rainy season) even under present climate has strong impacts on crop yields in RFA areas in Ethiopia, and this may be exacerbated in a future climate. 